\section{LONG SPINDLE DESIGN FOR} GRINDING

LUKAS RUDOLF, JIRI FRIES, OLDRICH UCEN

VSB-Technical University of Ostrava, Department of Production

Machines and Design, Czech Republic

DOI: 10.17973/MMSJ.2020_03_2019120

E-mail: lukas.rudolf@vsb.cz

This article is focused on design issues concerning the long spindle used to grind the internal pipe diameters. In the article an example of spindle design for an internal pipe diameter grinder can be found to process $11 \mathrm{~m}$ long pipes with external diameters ranging from 270 to $610 \mathrm{~mm}$. Furthermore, this article offers a theoretical proposal for the spindle stroke in connection with its engagement, taking into consideration the internal diameter of the ground pipe and the outside diameter of the grinding wheels. The pipes used in this example are designed for transport in the mining industry, requiring a high quality of inner pipes surface for their long service life.

KEYWORDS:

long spindle, grinding machine, pipe, internal diameter, spindle length

\section{INTRODUCTION}

To minimize the contamination of the conveyed medium it is necessary to remove iron scales from the inner surface of the pipe together with any superficial defects. The elimination of iron scales and superficial defects also has a positive effect on the overall pipe life, as it reduces the frequency of micro-break occurrence in the pipe walls during their lifetime [Hapla 2017] [Fries 2018]. To remove these defects the most appropriate technology used is the grinding method. When grinding the internal diameter of the pipes it is necessary to ensure that the removal of chips from the place of processing is sufficient enough, as well as the cooling. It should be noted that during grinding roughly $90 \%$ of output turns into the heat [Marek
2014]. For this reason it is advisable to leave one side of the pipe completely free to allow connection of a device removing the chips. A device supplying the refrigerant to the place of grinding is also a part of the spindle. With regard to the length of the pipe workpieces and the size of the workpiece surface, the optimal principle appears to be the use of axial grinding for internal rotating surfaces.

For the design of the grinder it is therefore appropriate to use the cursory fixed grinding wheels, located on the spindle. The spindle is in its length supported by a pair of supports, and it is attached to a moving carriage which ensures feed during the grinding. The layout of the grinding machine is shown in Fig. 1.

\section{INSTALATION REQUIREMENTS FOR SPINDLE}

With regard to the total length of $11 \mathrm{~m}$ pipe workpieces and the associated lining with a limited internal diameter of the pipe workpiece, the selected design layout does not allow us to create a sufficiently rigid spindle. This fact is typical for the axial grinding of the internal rotating surfaces.

When removing any surface defects from the internal diameter of the pipes high demands are not placed on the geometrical tolerances for the machined surfaces. Thanks to this fact the spindle does not have to be designed with any requirement to the minimum position changes in the area, caused by external forces and moments, as is the case for the regular construction of the spindles for grinders.

\subsection{Minimization of the spindle length}

Since there are no geometrical tolerances for the inner diameter of the spindle determined, it is possible to process pipes gradually from both sides by turning them around their vertical axes. This method of processing allows us to reduce the length of the required spindle. By minimizing the length of the spindle we can also reduce the necessary dimensions of the foundations to anchor these machines. The foundations for grinders must be suitably constructed to minimise vibration transfer to the machine surroundings [Rudolf 2017].

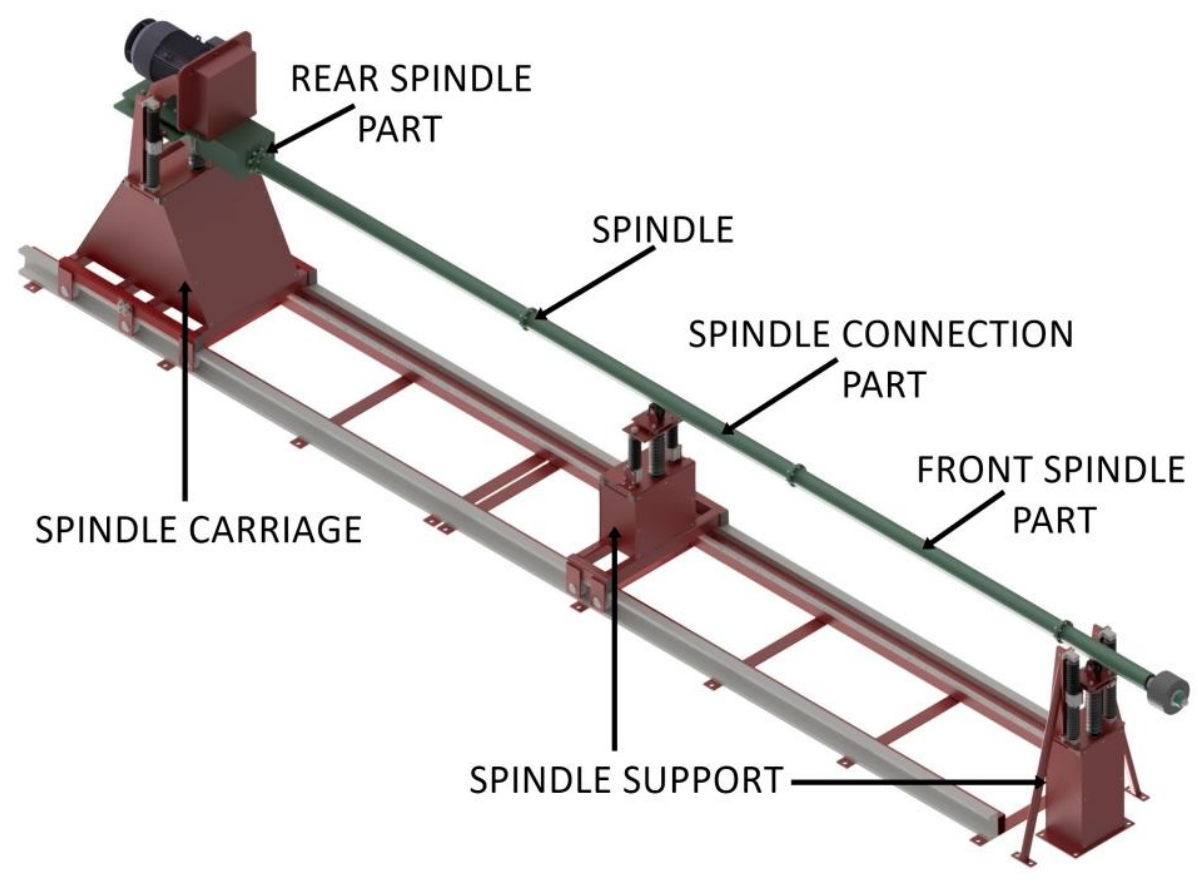

Figure 1. The grinder of an internal pipe diameter 


\subsection{The length of the spindle}

The spindle consists of the front part, on which the grinding wheels are clamped. Furthermore, there are several connecting parts that ensure the torque transfer, and the rear part, on which the torque from the spindle is transferred.

In view of the decreasing reliability of the machine in connection with an increasing number of components, it is appropriate to minimize the number of parts for the spindle. The optimum selection of bearings for the spindle is quite complex regarding the dimensional limitations of the spindle tube.

For the preliminary draft of individual parts for the spindle we must take into account the distance between the individual bearings of the spindle. This has been chosen with regard to the permissible deflection of the shaft between the bearings, (1) [Bolek 1989]. Where y is the shaft deflection between bearings $[\mathrm{mm}]$ and $\mathrm{L}$ the distance between the bearings $[\mathrm{mm}]$.

$y=\left(1 \cdot 10^{-4} \div 5 \cdot 10^{-4}\right) \cdot L[\mathrm{~mm}]$

This spindle is fixed using the self-aligning ball bearings along its whole length. To optimize the lifetime of the bearings it is necessary to follow their minimum load, which is given by the formula (2) where $P_{m}$ is the minimum equivalent load $[N]$ and $\mathrm{C}_{0}$ is the static load capacity of a bearing [N] [SKF 2007].

$$
P_{m}=0.01 \cdot C_{0}[\mathrm{~N}]
$$

The easiest way how to determine this load on the connecting part of the spindle is to use for calculation the weight of the spindle shaft itself. Since the spindle length of the front and rear sections is short, it is not possible to achieve the required load of the bearings using their own weight. The required load in the front part of the spindle is created by the weight of the grinding wheels, and at the rear part of the spindle it is done using the preload of the belt drive.

In the event of failure to maintain the adequate minimum bearing preload, slippage between the balls and their paths can occur, caused by the inertia force of the balls, running cages and friction in the lubricant. The resulting slippage has a negative impact on the life of the bearings, as it causes its increased wear and heating [SKF 2007].

Tab. 1. shows a comparison of several variants for the joint parts of the spindle in the designed example. For the preliminary draft, and depending on the bearings used, the diameter under bearing $33 \mathrm{~mm}$ was determined with a shaft shoulder of $44 \mathrm{~mm}$. For simplicity in this analysis the length of the joints was excluded.

\begin{tabular}{|l|c|c|c|}
\hline $\begin{array}{l}\text { The number of joint } \\
\text { parts of the spindle } \\
\text { [1] }\end{array}$ & 2 & 3 & 4 \\
\hline $\begin{array}{l}\text { Distance between } \\
\text { the bearings [mm] }\end{array}$ & 3,350 & $2,233.33$ & 1,675 \\
\hline $\begin{array}{l}\text { Maximum deflection } \\
\text { between the } \\
\text { bearings } y \text { [mm] }\end{array}$ & 6.327 & 0.659 & 0.262 \\
\hline $\begin{array}{l}\text { Allowed deflection } \\
\text { between the } \\
\text { bearings y [mm] }\end{array}$ & 1 & 0.67 & 0.5 \\
\hline
\end{tabular}

\begin{tabular}{|l|c|c|c|}
\hline $\begin{array}{l}\text { Reaction force in the } \\
\text { bearing [N] }\end{array}$ & 202.5 & 132.8 & 106.2 \\
\hline $\begin{array}{l}\text { Required reaction } \\
\text { force in the bearing } \\
\text { [N] }\end{array}$ & 112 & 112 & 112 \\
\hline $\begin{array}{l}\text { Number of bearings } \\
\text { [1] }\end{array}$ & 4 & 6 & 8 \\
\hline Suitable [1] & NO & YES & NO \\
\hline
\end{tabular}

Table 1. Preliminary analysis of the design variants

After selecting the three joint parts of the spindle, taking into consideration the size of the joint, one connecting piece of spindle has a total length of $2,176 \mathrm{~mm}$. The resulting characteristics of the spindle parts as shown in Fig. 2. and they are summarized in Tab. 2.
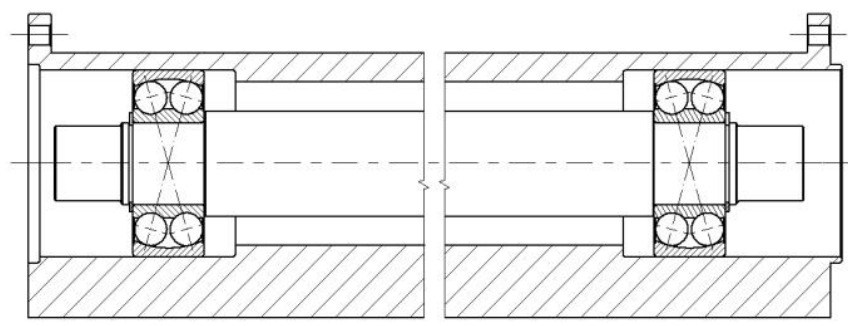

Figure 2. The connecting part of the spindle

\begin{tabular}{|l|c|}
\hline Distance between the bearings [mm] & 2,076 \\
\hline $\begin{array}{l}\text { Maximum deflection between the } \\
\text { bearings } y \text { [mm] }\end{array}$ & 0.619 \\
\hline $\begin{array}{l}\text { Allowed deflection between the } \\
\text { bearings [mm] }\end{array}$ & 0.623 \\
\hline Reaction force in the bearing [N] & 126.4 \\
\hline $\begin{array}{l}\text { Required reaction force in the } \\
\text { bearing [N] }\end{array}$ & 112 \\
\hline Suitable [1] & YES \\
\hline
\end{tabular}

Table 2. Selected option of the spindle joint parts

\subsection{Minimising vibrations transmissions}

With regard to the length of the lining and the initial condition of the internal surface of the workpieces there are significant vibrations occurring during the grinding operations. Any transfer of these vibrations must be maximally reduced. To reduce this transfer it is appropriate to join the individual parts of the spindle using the couplings with flexible elements. In the completed case elastomeric and wave couplings were used. These couplings, in addition to good vibration control, also allow axial movement and thus help to solve the thermal expansion of the spindle that, with regard to its overall length, must also be taken into account. The selected joints also partially allow to compensate for the parallel and angular misalignment of the individual spindle parts [ $+W$ 2013].

The transmissibility of the vibrations form the spindle tube on the mobile carriage of the spindle is reduced by fitting it with 
over 16 rubber bushings. The guides of the fixed and moving supports are also mounted using the rubber bushings.

\subsection{Torque transfer to the spindle}

For torque transfer from the engine to the spindle a v-belt drive was selected that allows slippage during spindle overloading. Thus, it fulfils the function of the overrunning clutch, protecting the engine from damage that can occur when the spindle is overloaded due to incorrect operation of the grinder. The rear section of the spindle, which enables this transfer, is illustrated in Fig. 3.

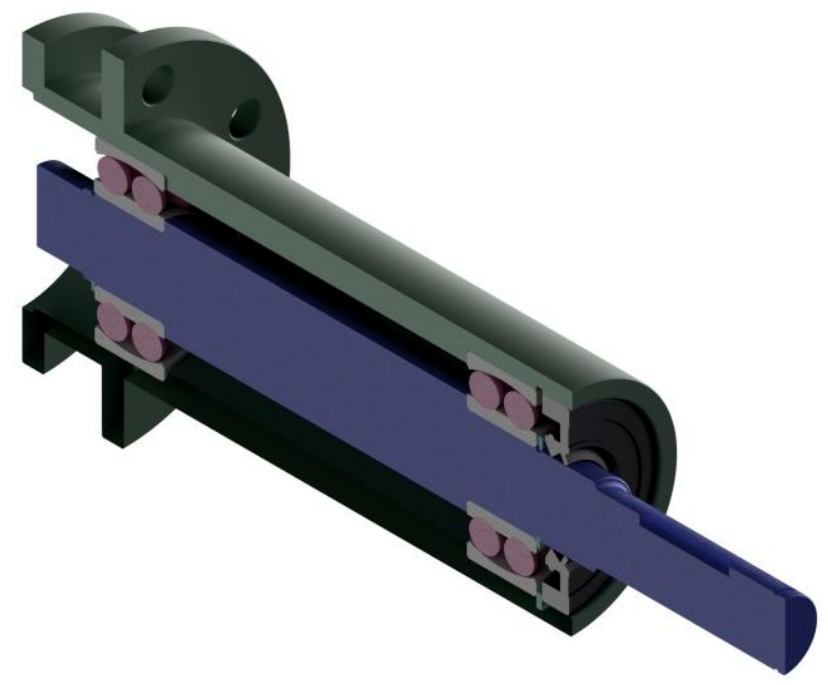

Figure 3. Rear spindle part

\subsection{Easy exchange of grinding wheels}

Despite the extraction connected to the loose side of the grinder, and the intense cooling medium intake into the area of cutting, it is very difficult to remove the chips from the ground area. Thus, intensive fouling of the grinding wheels can occur. For this reason the total grinding wheels area is increased by placing the four grinding wheels in a row. Still it is necessary to provide truing quite frequently and replace the grinding wheels often.

These wheels are fixed using flanges, based on the standard [ČSN 20 1524). The grinding wheels are seated at the quenched case, which increases the lifetime of the spindle. The end part of the spindle is equipped with a hexagon bar for its easy arrestment when replacing the wheels. The overall design of the front part can be seen in Fig. 4.

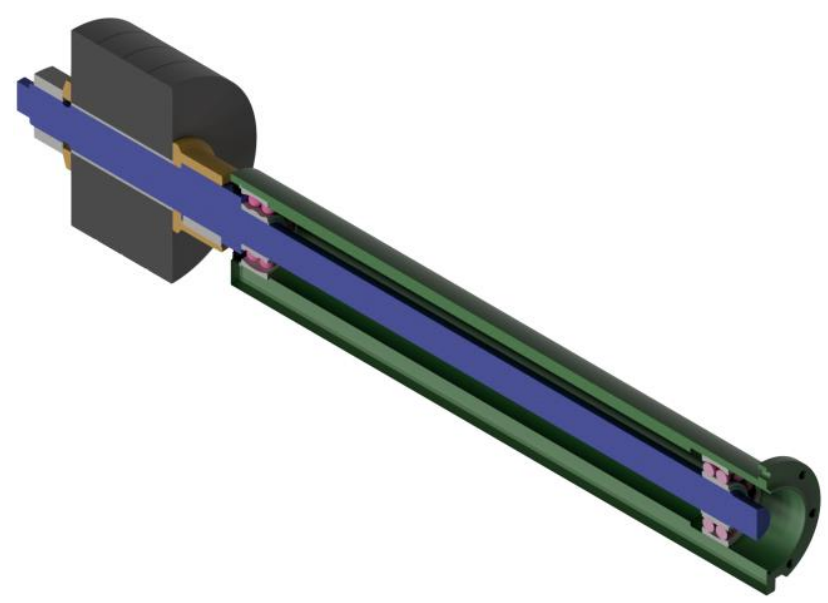

Figure 4. Front spindle part

\section{THE FORCES OCCURRING DURING GRINDING}

When grinding there is the total cutting force occurring between the wheel and the workpiece in the usual direction. This force can be divided into three parts perpendicular to one another, as shown in Fig. 5. The largest share of power is the perpendicular force acting on the ground surface. We refer to it as to the passive force $F_{p}$. The force to be applied in the traverse direction is marked as $F_{F}$ and forces applied in the direction of the cutting speeds $F_{c}$. The size of the cutting force that is generated by the spindle drive of the grinder can be determined using an empirically derived formula [Humar 2015].

$F_{C}=2.5 \cdot v_{w}^{0,5} \cdot f_{a}^{0,4} \cdot a_{e}^{0,4} \cdot d_{w}^{0,3}[\mathrm{~N}]$

Where $v_{w}$ is the circumferential speed of the workpiece $[\mathrm{m} / \mathrm{min}], \mathrm{f}_{\mathrm{a}}$ the axial movement of the grinder tabletop for one revolution of the workpiece, $a_{e}$ is working width $[\mathrm{mm}]$ and $d_{w}$ is the diameter of the workpiece [mm].

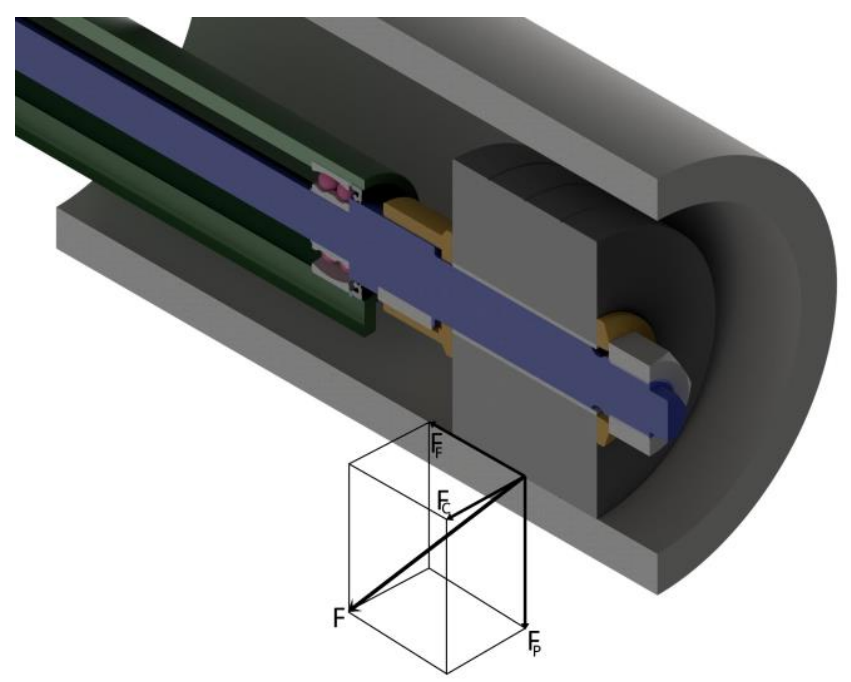

Figure 5. The forces distribution

The size of the passive force that due to the selected design of the layout consists of its own spindle gravity depending on its ejection, ranges in extent [Humar 2015]

$$
F_{P}=(1.2 \div 3) \cdot F_{C}[\mathrm{~N}]
$$

and also according to [ISO 16089] in range.

$$
F_{P}=(2 \div 10) \cdot F_{C}[\mathrm{~N}]
$$

Since the theoretical dispersion of the passive force size is considerable here, it is necessary to use its minimum and maximum value when designing it, and to adjust the spindle dimensions accordingly, especially its tube. The traverse force consists of carriage spindle driving, implemented by the means of pinion engagement in the electric gearbox into the rack attached along the guiding profile of the carriage fairlead.

\section{GRINDER TILTING}

Thanks to the design layout with cursorily placed grinding wheels there is the risk of tilting the grinder over in the event the spindle travels a large distance behind the fixed support during the grinding operation. Even though the spindle is "lifted" during the grinding by passive forces, thanks to its low stiffness this effect is not substantial here. Therefore, in the course of its design it is necessary to monitor the location of the grinder gravity center carefully. The center of gravity must 
be placed before the stationary support axis of rotation, to prevent tilting of the grinder. Despite this measure it is appropriate to fix the roller wheel of the spindle carriage from the top. This can be done using the guides for roller wheel using a u-profile. These guides can prevent the tilt of the grinder when it is overbalanced. In case of accidental tilting over the roller wheel hit the top part of the guides. This can lead to the emergence of a significant impact force that can have a negative effect on the welded parts of the grinder structure. However, this system eliminates any serious damage to the spindle due to the impact of the rotating workpieces pipe.

\section{THE DEFLECTION OF THE SPINDLE DEPENDING ON THE LINING}

Thanks to the large positioning of the spindle in the course of grinding there is some deflection occurring. For this reason, during the design of the spindle the FEM analyses of the total deflection of the spindle were made. It was time consuming to appropriately define the dimensions of the spindle so as to maintain the desired passive forces, and at the same time to achieve an acceptable deflection of the spindle. These analyses were performed on an idealized spindle excluding the considered cutting and slide forces. The cutting force causes the spindle to bend in a horizontal direction depending on the inner radius of workpiece and thus reduces the deflection of the spindle in the direction of the weight influence.

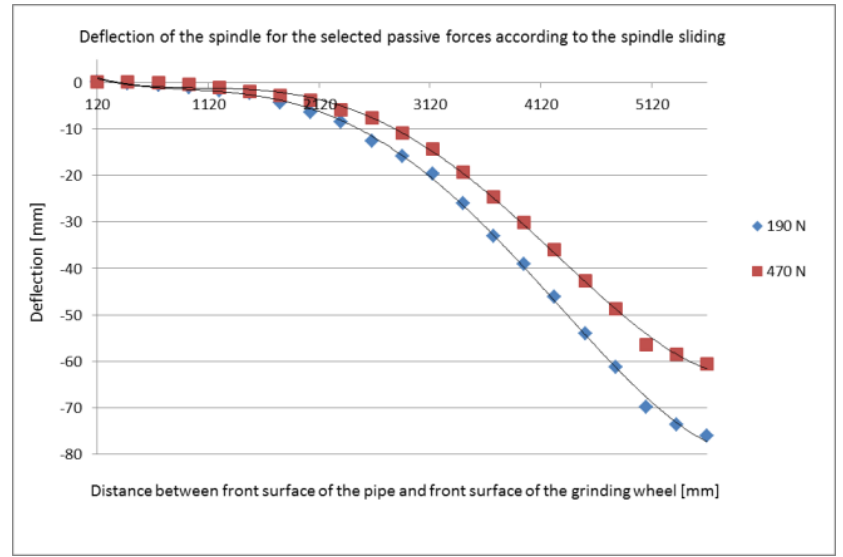

Figure 6. The course of deflection depending on the ejection for the size of a passive force of $190 \mathrm{~N}$ and $420 \mathrm{~N}$
The deflections in the complete spindle, depending on the size of the passive force, are shown in Figs. 6, 7. and 8. The limit values of passive forces were determined on the basis of the relationship (4) and (5), taking into account the cutting force calculated as (3). Tab 3 . shows the minimum and maximum value of the $F_{p}$.

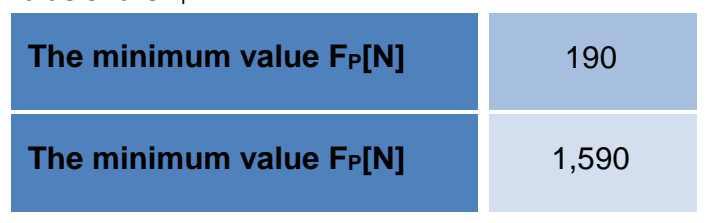

Table 3. Limit values for passive forces

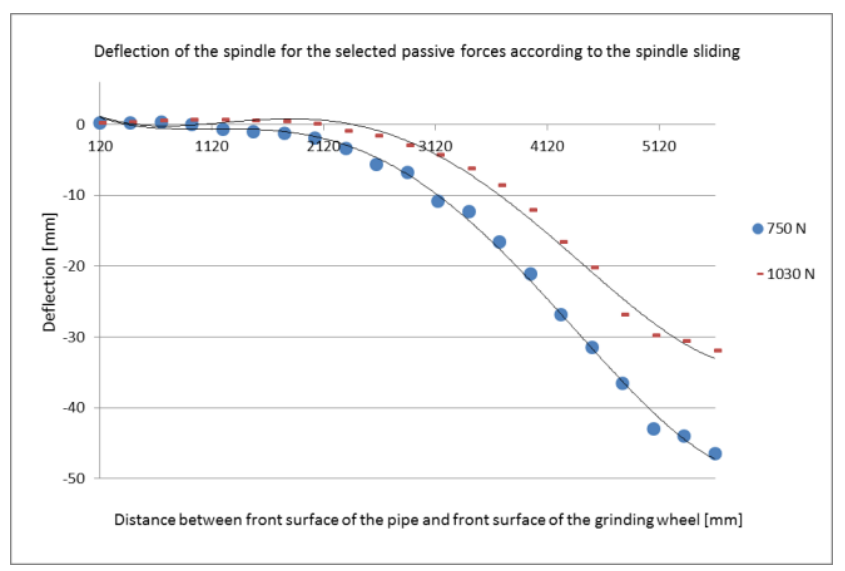

Figure 7. The course of deflection depending on the ejection for the size of a passive force of $750 \mathrm{~N}$ and 1,030 N

On the basis of the FEM analyses the Tab. 4. was processed, which contains the recommended size of the passive forces in relation to the ejection of the spindle and a diameter of the grinding wheels, or eventually on the inner diameter of the pipe workpiece.

\subsection{Passive force control}

In the course of the processing the passive force size is affected by the lift of the spindle. The spindle lift is done using the actuators which are located in the spindle carriage, both in its fixed and moving support. The optimum spindle lift that was designed using the FEM analysis must be corrected by monitoring the load of the grinder electromotor. It is then possible to determine the optimal course of the grinder lift depending on the ejection of the pipe workpiece, or on the selected diameter of the grinding wheels.

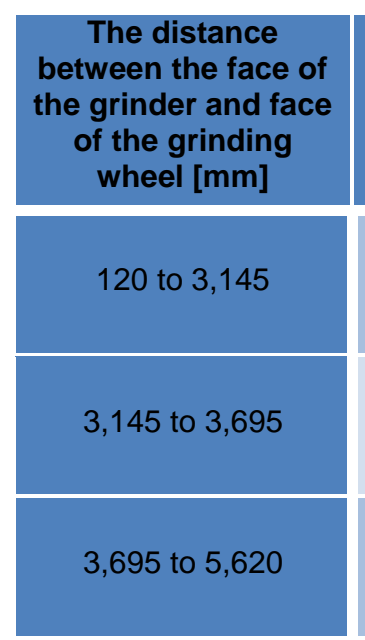

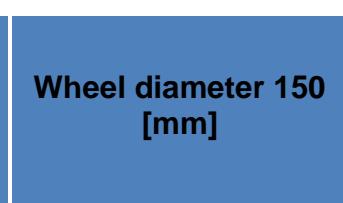

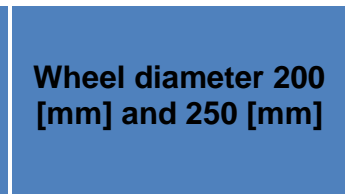

$190 \mathrm{~N}$ to $1,310 \mathrm{~N}$
Proceed from the
second set of criteria
Proceed from the
second set of criteria

Proceed from the

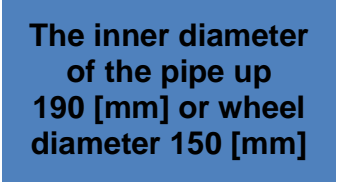

$190 \mathrm{~N}$ to $1,310 \mathrm{~N}$ second set of criteria

Proceed from the second set of criteria
The inner diameter of the pipe over $190[\mathrm{~mm}]$ or wheel diameter $200[\mathrm{~mm}]$ or $250[\mathrm{~mm}]$

Proceed from the second set of criteria

Proceed from the second set of criteria

$750 \mathrm{~N}$ to $1,310 \mathrm{~N}$

$470 \mathrm{~N}$ to $1,310 \mathrm{~N}$

Table 4. Recommended sizes of passive forces in relation to the ejection of the spindle, the grinding wheels diameter, and the internal diameter of the pipe workpiece 


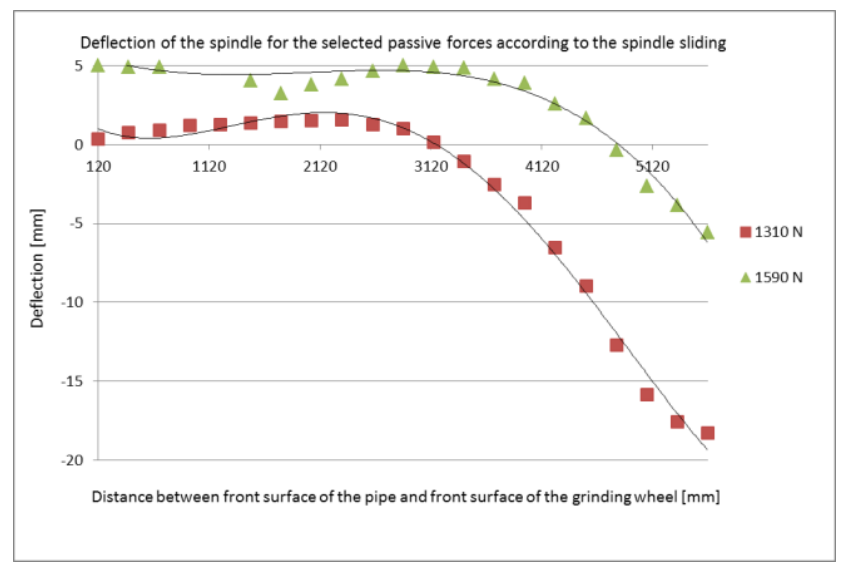

Figure 8. The course of deflection depending on the ejection for the size of a passive force of 1,310 $\mathrm{N}$ and 1,590 $\mathrm{N}$

However, this stroke must be further adjusted using grinder electromotor load data, because of changes in the diameter of the grinding wheels during their wear and tear by the grinding process. For an illustration Fig. 9. displays one uncorrected course of the spindle lift based on the FEM analyses.

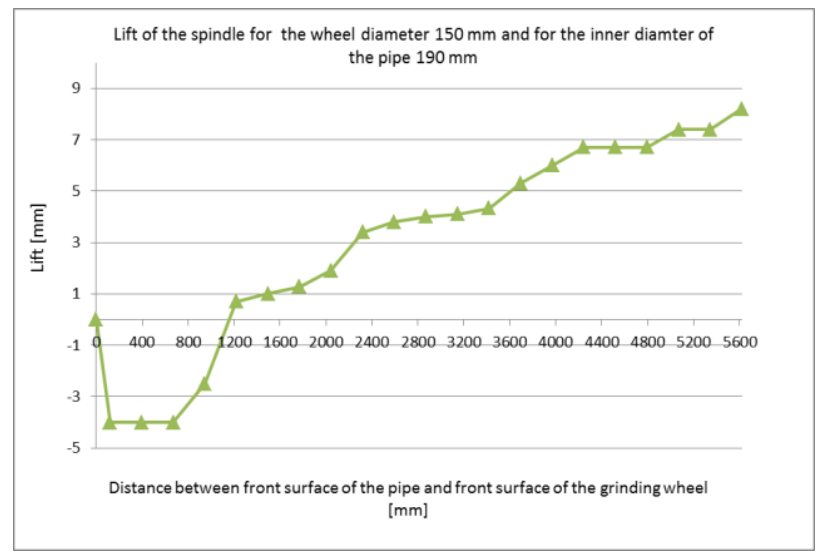

Figure 9. The theoretical course of the spindle lift for the $150 \mathrm{~mm}$ diameter wheel or for a $190 \mathrm{~mm}$ internal diameter of the pipe.

\section{Conclusions}

In the design of the grinder spindle to grind the internal diameters of pipes it is necessary to optimize the dimensions of the individual parts of the spindle, with regard to the specified deflection and external force load according to the requirements of the worked surface. This effort is however complicated by the great scope of the passive force acting on the grinding wheels. There is also the issue of the chip removal from the place of processing, and thus the front section of the spindle shall be, due to the fouling up of the wheels, structurally designed to facilitate easy and fast replacement of these grinding wheels and aid in the removal of the chips. The designed spindle, which consists of a short front, back and several long connecting parts, allows for the easy modification in the tube processing of shorter tubes, without the necessity to change the structure of the other grinder parts by removing one or two joining parts of the spindle.

\section{ACKNOWLEDGEMENTS}

This article has been written in connection with the project The research and analysis of modern technologies in manufacturing practice, reg. no. SP2018/3 supported by Specific Research program financed by the Ministry of Education, Youth and Sports.

\section{REFERENCES}

[Bolek 1989] Bolek, A., Kochman, J. Parts of machines 5. Revised edition (in Czech). Praha: SNTL, 1989. ISBN 80-030-0046-7

[CSN 20 1524] Standart CSN 20 1524: 1977 Flanges for clamping of abrasive wheels. (In English) Prague : UNMZ, 1975.

[ISO 16089] Standart CSN EN ISO 16089: 2015 Machine tools Safety - Stationary grinding machines. Prague : UNMZ, 2015.

[Marek 2014] Marek J, et al. Construction of CNC machine tools III. (in Czech). Praha: MM publishing, 2014. ISBN 978-80-260-6780-1

[Hapla 2017] Hapla, T., et al. Optimization of the rod eye for a tilting platform. SGEM 2017, 13, 631-620, 13142704. DOI: $10.5593 /$ sgem 2017/13/S03.078

[Humar 2005] Humar, A. Technology I - Machinery technology - 3rd part: Interactive multimédia text for bachelor and master study programs [online] (in Czech). Brno, 2005 [cit. 2018-03-08]. Available from: http://ust.fme.vutbr.cz/obrabeni/opory-

save/Dokoncovaci_a_nekonvencni_metody_obrabe ni/TI_TO-3.cast.pdf

$[R+W$ 2013] $R$ \& $W$ Antriebselemente $\mathrm{GmbH}$. Precision couplings [online]. Klingenberg, 2013 [cit. 2018-0308]. Available from: https://www.remtechnik.cz/files/fck_userfiles/file/RW/RW-prehledhridelovych-spojek_en.pdf

[Rudolf 2017] Rudolf, L., et al. The method of detecting movements of the machine tool foundations. SGEM 2017, 13, $893-900,1314-2704 . \quad$ DOI: $10.5593 /$ sgem 2017/13/S03.113

[SKF 2007] SKF, Self-aligning ball bearings [online] (in Czech). 2007 [cit. 2018-03-08]. Available from: http://www.exvalos.cz/soubory/File/Hlavni_katalog _SKF/6000_CS_03_Naklapeci\%20kulickova\%20lozis ka.pdf

[Fries 2018] Fries, J., Hapla, T. Influence affecting the lifetime of belt conveyor's drive drums. Tehnicki Vjesnik, Osiek. Volume 25, May 2018, Pages 7-14. DOI: 10.17559/TV-20140411120832.

\section{CONTACTS}

Ing. Lukas Rudolf

Assoc. prof. Ing. Jiri Fries, Ph.D.

Ing. Oldrich Ucen, Ph.D.

VSB-Technical University of Ostrava, Department of Production Machines and Design

17. listopadu 15/2172, Ostrava, 708 33, Czech Republic

E-mail: lukas.rudolf@vsb.cz, jiri.fries@vsb.cz, oldrich.ucen@vsb.cz 